\title{
Does Microbicide Use in Consumer Products Promote Antimicrobial Resistance? A Critical Review and Recommendations for a Cohesive Approach to Risk Assessment
}

\author{
Jean-Yves Maillard, Sally Bloomfield, ${ }^{2}$ Joana Rosado Coelho, ${ }^{3}$ Phillip Collier, ${ }^{4}$ Barry Cookson, ${ }^{5}$ \\ Séamus Fanning, ${ }^{6}$ Andrew Hill, ${ }^{7}$ Philippe Hartemann, ${ }^{8}$ Andrew J. Mcbain, ${ }^{9}$ Marco Oggioni, ${ }^{10}$ \\ Syed Sattar, ${ }^{11}$ Herbert P. Schweizer, ${ }^{12}$ and John Threlfall ${ }^{13}$
}

The increasing use of microbicides in consumer products is raising concerns related to enhanced microbicide resistance in bacteria and potential cross resistance to antibiotics. The recently published documents on this topic from the European Commission have spawned much interest to better understand the true extent of the putative links for the benefit of the manufacturers, regulators, and consumers alike. This white paper is based on a 2-day workshop (SEAC-Unilever, Bedford, United Kingdom; June 2012) in the fields of microbicide usage and resistance. It identifies gaps in our knowledge and also makes specific recommendations for harmonization of key terms and refinement/standardization of methods for testing microbicide resistance to better assess the impact and possible links with cross resistance to antibiotics. It also calls for a better cohesion in research in this field. Such information is crucial to developing any risk assessment framework on microbicide use notably in consumer products. The article also identifies key research questions where there are inadequate data, which, if addressed, could promote improved knowledge and understanding to assess any related risks for consumer and environmental safety.

\section{Introduction}

$\mathbf{M}$ ICROBICIDES ARE CHEMICAL AGENTS that are commonly used for the control or destruction of microorganisms in a wide range of applications, including consumer products and also in the healthcare, food, water, and manufacturing industries. Such is the extent of their use, that it is now commonplace to find many products that contain microbicides (e.g., household cleaning products, toothpastes, mouthwashes, hand cleaning products, work surfaces, garments, underwear, pencils, and textiles). Although certain microbicides have been around for centuries, their use, in general, saw a decline with the advent of antibiotics. It is only within the last 60 years or so that the diversity of microbicides, and the breadth and intensity of microbicidal usage has increased. Such a revival of interest in microbicide use is due to mounting antibiotic resistance, emergence/ re-emergence of many infectious diseases as well as changing life styles and demography, ${ }^{2,29}$ but also a rise in cleanliness and hygiene and a better perception of the public issues around microbial pathogens. ${ }^{16}$ More recently, outbreaks of multidrug-resistant bacterial diseases in the healthcare

${ }^{1}$ Cardiff School of Pharmacy and Pharmaceutical Sciences, Cardiff University, Cardiff, United Kingdom.

${ }^{2}$ London School of Hygiene and Tropical Medicine, International Scientific Forum on Home Hygiene, London, United Kingdom.

${ }^{3}$ INESC-ID/IST, Technical University of Lisbon, Lisbon, Portugal.

${ }^{4}$ School of Contemporary Sciences, University of Abertay Dundee, Dundee, United Kingdom.

${ }^{5}$ Division of Infection \& Immunity, Faculty of Medical Sciences, University College London, London, United Kingdom.

${ }^{6}$ UCD Centres for Food Safety and Molecular Innovation \& Drug Design, School of Public Health, Physiotherapy \& Population Science, University College Dublin, Dublin, Ireland.

${ }^{7}$ Epidemiology, Surveillance and Risk Group, Animal Health and Veterinary Laboratories Agency, Weybridge, United Kingdom.

${ }^{8}$ Départment Environment et Santé Publique, Faculté de Médecine, Vandoeuvre-les-Nancy, France.

${ }_{9}^{9}$ School of Pharmacy and Pharmaceutical Sciences, the University of Manchester, Manchester, United Kingdom.

${ }^{10}$ Laboratory of Molecular Microbiology and Biotechnology, Università degli Studi di Siena, Siena, Italy.

${ }^{11}$ Centre for Research on Environmental Microbiology, University of Ottawa, Ottawa, Ontario, Canada.

${ }^{12}$ Department of Microbiology, Immunology and Pathology, College of Veterinary Medicine and Biomedical Sciences, Colorado State University, Fort Collins, Colorado.

${ }^{13}$ Health Protection Agency, London, United Kingdom. 
settings, increased awareness of the importance of infection prevention measures, allied to an improved understanding by consumers of the microbial nature of infectious diseases, have contributed to the increased usage of microbicides also in the domestic environment. This rather sudden increase in microbicide use has prompted questions from the European Commission as to their contribution to reducing infection risks and concerns to the possible link(s) between extensive microbicide use and the emergence of antimicrobial resistance. ${ }^{31}$ However, it is acknowledged that the main reason for the worldwide increase in antibiotic resistance is undeniably linked to the usage and abuse of antibiotics in human and veterinary medicine. ${ }^{32}$ It is, however, difficult to estimate the impact of other contributions such as the use of biocides or the use of antibiotics in industrial processes.

The past 3 years have seen a limited increase in scientific output on microbicidal resistance in bacteria to at least begin to address some of the many deficiencies in our knowledge gaps as identified by the SCENIHR opinion article. ${ }^{32} \mathrm{Mi}-$ crobial interactions with, and resistance to, microbicides, however, continue to remain poorly understood and studied, when compared to resistance to chemotherapeutic antibiotics. This is compounded by the lack of unity among researchers on what constitutes resistance to a microbicide, as demonstrated by the variety of definitions and resistance measurement protocol in the literature, and by the lack of evidence on the use of microbicides to control the spread of infections. ${ }^{7}$

This article is a position document and not an extensive review of the literature. It provides some key references and refers to comprehensive reviews such as the one published by the Scientific Committee for Emerging and Newly Identified Health ${ }^{31,32}$ and the Scientific Committee for Consumer Safety. $^{30}$

The objectives of this position document are to: (1) clearly establish and set key definitions of relevant terms, (2) provide a consensus view on the methods to study changes in bacterial susceptibility to microbicides, (3) discuss the possible development of bacterial resistance to microbicides and antibiotics following their usage, and (4) propose key points toward developing a risk assessment framework for microbicides in the context of emerging bacterial resistance. This document will focus only on vegetative bacteria, including bacterial biofilms.

\section{Toward the Harmonization of Terminology}

There is a need to harmonize terminology. The term "biocide" (kills anything living) as currently used, is too broad and includes, along with disinfectants and antiseptics, fungicides, algicides, rodenticides, insecticides, and biological agents such as bacteriophages and some bacteria (Directive $98 / 8 / \mathrm{EC}){ }^{9}$ This is too broad a meaning when referring to chemicals that can kill microorganisms and/or inhibit their replication. Therefore, we recommend the terms "microbicide" and "microbistat," respectively, instead of biocide, which is used in the European Directive in its broader sense. Thus, microbicides include disinfectants, preservatives, and antiseptics with activity against bacteria, fungi, spores, protozoa, cysts, algae, and prions (all microorganisms), but exclude antibiotics. There is also widening acceptance of these terms in the United States ${ }^{33}$ and Canada. The terms bacte- ricide, fungicide etc. should still be used to denote activity against specific microorganisms.

There is no clear consensus in the scientific community on the definition of bacterial resistance to microbicides. We recognize that the definition of "resistance" is key, but this is far too often subject to different interpretations in the peerreviewed literature. Such differences in defining a crucial term contribute to the difficulty in comparing data and might, in some cases, communicate the incorrect information about a microbicide/target bacteria interaction. For example, resistance has often been used to describe an increased minimum inhibitory concentration (MIC) to a given microbicide in bacteria, but equally to describe an increase in minimum bactericidal concentration (MBC) or the survival of bacteria at an in-use concentration of a microbicide present in a product. ${ }^{16}$ We propose that resistance is defined as " $a$ change in susceptibility to a microbicide that renders it ineffective against a micro-organism that was previously susceptible to that microbicide." This needs to be distinguished from reduced susceptibility, which refers to the increases in MIC or MBC as mentioned above, but where microbicides or microbicidecontaining products are still effective for their intended purpose (at their in-use concentration), that is, inhibition or destruction of the target microorganism(s), but also from intrinsic resistance which is an innate property of a microorganism. When considering the target microorganism, it is important to take account of the variability of susceptibility between strains of the same species (see below).

Information from the literature is often difficult to interpret and compare, because of the lack of consensus definitions and the wide range of laboratory methodologies used to measure a change in susceptibility or resistance. Thus, the risk associated with the use of a given microbicide on the development of microbial resistance is often difficult to ascertain.

\section{Factors Involved in the Development of Reduced Susceptibility or Resistance to Microbicides in Vegetative Bacteria}

There are several factors/parameters that can affect the efficacy of microbicides and these have generally been well reported. ${ }^{15,31}$ However, less well reported are the factors that contribute to the emergence of reduced susceptibility or resistance to microbicides in bacteria. These factors can be divided into three main groups: (1) those that are related to the microbicide, (2) those inherent to the microorganism, and (3) those inherent to the biocidal product formulation and its usage (see Table 1).

\section{Factors related to the microbicide}

Microbicides have a wide variety of chemistries. We know very little of the mechanisms of action of microbicides against bacteria and the development of microbicide resistance. This is in stark contrast with antibiotics that have specific target(s) against the bacterial cells and for which, our understanding of how bacteria may develop resistance against them is more developed. The best-studied microbicide is the bisphenol triclosan, and to a lesser extent glutaraldehyde, the biguanide chlorhexidine, the quaternary ammonium compounds (QACs) benzalkonium chloride and cetrimide, chlorinated bisphenols, ${ }^{30,31}$ hydrogen peroxide, 
Table 1. Factors Contributing for the Development of Reduced Susceptibility or Resistance in Bacteria

\begin{tabular}{|c|c|c|c|}
\hline \multirow[b]{2}{*}{ Factors } & \multirow[b]{2}{*}{ Potential risk } & \multicolumn{2}{|c|}{ Examples of microbicide and comments } \\
\hline & & Triclosan & Hydrogen peroxide \\
\hline \multicolumn{4}{|c|}{ Inherent to the microbicides } \\
\hline Mechanism of action & Primary (single) target site & $\begin{array}{l}\text { Target enoylACPreductase } \\
\text { at a low concentration } \\
\text { Selection of efflux pump } \\
\text { expressing mutants at low } \\
\text { to high concentrations }\end{array}$ & $\begin{array}{l}\text { Primarily nucleic acid damage } \\
\text { Require penetration in the } \\
\text { bacterial cytoplasm }\end{array}$ \\
\hline Concentration & $\begin{array}{l}\text { Rapid decrease in activity upon } \\
\text { dilution }\end{array}$ & $\begin{array}{l}\text { High-concentration exponent } \\
\text { (rapidly loses activity upon } \\
\text { dilution) }\end{array}$ & Low-concentration exponent \\
\hline Formulation & $\begin{array}{l}\text { Antagonistic effect of excipient } \\
\text { pH incompatibility } \\
\text { Segregation (micelles) }\end{array}$ & $\begin{array}{l}\text { Require solubilizers to attain } \\
\text { high concentration }\end{array}$ & $\begin{array}{l}\text { Rapid loss of activity (product } \\
\text { shelf life?) }\end{array}$ \\
\hline \multicolumn{4}{|c|}{ Inherent to the bacteria ${ }^{a}$} \\
\hline Type & Intrinsic resistance & $\begin{array}{l}\text { Pseudomonas spp. Burkholderia } \\
\text { spp. }\end{array}$ & $\begin{array}{l}\text { Resistant environmental bac- } \\
\text { teria isolated from endo- } \\
\text { scope washer disinfector }\end{array}$ \\
\hline Metabolism & Low-metabolic activity & $\begin{array}{l}\text { Reduced activity with low } \\
\text { metabolism }\end{array}$ & Independent of metabolism \\
\hline Resistance mechanisms & $\begin{array}{l}\text { Overexpression } \\
\text { Mutation to constitutive } \\
\text { expression }\end{array}$ & Efflux & $\begin{array}{l}\text { Degradation (catalase, super- } \\
\text { oxide dismutase) }\end{array}$ \\
\hline \multicolumn{4}{|l|}{ Inherent to application } \\
\hline Exposure time & $\begin{array}{l}\text { Presence of sub-MIC } \\
\text { concentration }\end{array}$ & $\begin{array}{l}\text { Loses rapidly activity upon } \\
\text { dilution }\end{array}$ & - \\
\hline Residual concentration & Selective pressure & & No residual concentration \\
\hline Soiling & Reduced bioavailability & 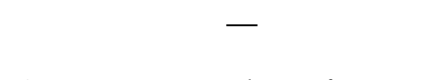 & $\begin{array}{l}\text { Affected by organic matter } \\
\text { (mopping up) }\end{array}$ \\
\hline Material/surface & $\begin{array}{l}\text { Incompatibility } \\
\text { Reduced penetration }\end{array}$ & $\begin{array}{l}\text { Concentration release from } \\
\text { surfaces? }\end{array}$ & $\cos 20$ \\
\hline
\end{tabular}

${ }^{a}$ Biofilm and bacterial endospores are not considered in this table.

MIC, minimum inhibitory concentration.

and oxygen, and chlorine releasing compounds. Some information on the mechanisms of action of microbicides may come indirectly from studies on toxicity against mammalian cells, for example, the interaction of hydrogen peroxide with DNA. ${ }^{14}$ For other microbicides, the information available is often anecdotal, whereby a specific chemistry has been studied against one particular type of bacterium or bacterial enzyme. Information on the modes of action can be obtained indirectly with determination and knowledge of the concentration exponent, which provides some indication of the nature of the interaction of a microbicide with a specific bacterium. ${ }^{8}$ Attempts have rarely been made to determine the mode of action using radiotracer studies that assess effects of antimicrobials on DNA, RNA, protein, or cell wall biosynthesis akin to what is routinely performed to study the target effects of antibiotics.

Bacteria can survive exposure to microbicides following a number of strategies (mainly mutation, modification/ degradation of the microbicide, and changes induced by a stress response) that can occur on their own or together. Microbicides often have multiple target sites within a given bacterium and, with this in mind, the development of bacterial resistance to microbicides is less likely to arise when compared to that for most antibiotics, notably the selection for multiple mutations. The nature (importance) of the target sites, the number of target sites affected (damaged), and the degree of damage inflicted by the microbicide, determine whether the microbicide has a lethal or inhibitory effect. In terms of resistance, microorganisms are more likely to survive a microbicide exposure if fewer than a critical number of sites are damaged. ${ }^{16}$ This is demonstrated with triclosan (at sublethal concentrations) for which, a defined target gene mutation leading to reduced susceptibility to the bisphenol has been well documented in many bacterial genera and species. Mutational changes in the enoyl acyl carrier reductase protein has been linked to a reduced susceptibility to triclosan in bacteria. ${ }^{12}$ More recently, a change in the metabolic pathway in Staphylococcus aureus and Salmonella enteric serovar typhimurium was shown to contribute to reduced susceptibility to triclosan. ${ }^{34}$ If an interaction with a specific target site can be identified, then such an interaction may be susceptible to mutation, which, if viable, may lead to a resistant or a reduced susceptibility phenotype, as exemplified with the numerous studies on triclosan.

The importance of the multiple target interaction makes the development, and genetic transfer, of resistance less likely.

A given microbicide may become diluted, degraded, or modified, thus reaching the microbial target in concentrations lower than those applied and required for its effective action. ${ }^{30}$ Effective modification/degradation of aldehydes (e.g., via aldehyde dehydrogenase), metallic salt (through 
transformation from the ionic to the metal form), hydrogen peroxide (e.g., via catalase and super oxide dismutase), and other microbicides such as biguanide, QACs, and phenolics have been reported in bacteria. ${ }^{16,31}$ The rate of such degradation/modification may be too slow (e.g., for phenolics) to confer resistance when considering the generally short usage duration of biocidal products. As such, the modification or degradation of the microbicide may give rise to a reduced susceptibility phenotype, but not necessarily a resistant phenotype. ${ }^{16}$ Long-term microbicide exposure may occur in the environment, although the effect on the microbial flora has not been investigated.

The applied concentration of a microbicide, and particularly the concentration reaching the bacterial target site, is key for activity. ${ }^{16,20}$ Exposure to a subinhibitory concentration is likely to exert a selective pressure that will eventually produce a stress response leading to a change in gene expression. Such a change, whether transient or permanent, will lead to the selection for resistant bacteria or bacteria with a reduced susceptibility. ${ }^{16,31}$ The effect of dilution on the efficacy of microbicides can be measured by the concentration exponent ${ }^{8}$ and as such, this provides information on the microbicides at risk (i.e., those with a high-concentration exponent) of selecting for resistance when diluted or used at a low concentration; that is, during which, the concentration would decrease rapidly to an MIC or sub-MIC level. Biocidal products used at a low concentration for preservation or for their residual effect on surfaces might thus be particularly prone to the development of resistance.

\section{Factors related to the microorganisms}

Different microorganisms are known to exhibit different susceptibilities to microbicides. The Spaulding classification was an excellent approach to rate the susceptibility of microorganisms to microbicides and is generally still valid, although it has required amending to bring it in line with current knowledge (Table 2). ${ }^{21}$ This classification addresses the intrinsic resistance of microorganisms. Nevertheless, within specific microbial groups, exceptions exist with regard to the microbicides under consideration.

Microbicides, even at a low concentration, can exert selective pressure on bacteria. This is often evident in the observation of an extended lag phase of the bacterial growth curve in the presence of a subinhibitory concentration of that microbicide. ${ }^{11}$ Such observations support the concept of an adaptation time (for example, involving the induction of specific mechanisms such as efflux, altered outer membrane protein expression) necessary for the bacteria to respond to the selective pressure and resume normal growth. Insight into the underlying mechanisms of adaptation can be provided through application of techniques such as microarrays, qRT-PCR, and metabolomic protocols. These have recently helped in confirming the degree of expression of major regulators such as RpoS and SoxS, which may eventually lead to the altered expression of efflux pumps, changes in membrane composition, porin expression, quorum sensing, or changes in metabolic processes. ${ }^{16,34}$ How widespread such genetic responses are in the ability of bacteria to survive and develop reduced susceptibility or resistance to a microbicide is unknown. In addition, the induction/adaptation time can be transient and so translate into an unstable resistance phenotype; that is, the bacteria revert to susceptibility to that microbicide when its selective pressure is removed. The expression of plasmid-encoded resistance mechanisms has often been described as "transient." Some bacteria may revert to a susceptible phenotype following plasmid loss, an indicator that they are losing an un-needed extra genetic burden, which would otherwise make their growth unfavorable when the microbicidal selective pressure is removed. Chromosomally encoded resistance mechanisms (e.g., efflux pumps in Pseudomonas spp.) that are not a burden may be maintained/transcribed for many, or indeed all, generations (i.e., they either do not confer an energy burden, or at least

Table 2. Microbial Susceptibility

to Microbicides-Revised Spaulding Classification

\begin{tabular}{lll}
\hline Levels of microbicidal action & & Microbial resistance \\
\hline High level & Prions & Unknown \\
Intermediate & Bacterial endospores & Expression of resistance \\
level & Protozoal oocysts & mechanisms \\
& Nonenveloped viruses & Adaptation/structure \\
& Mycobacteria & \\
& Protozoal cysts & Expression of resistance \\
& Fungal spores & mechanisms \\
& Vegetative Gram-negative & Unknown \\
& bacteria & Unknown \\
Lungi & Protozoa (trophozoites) \\
& Vegetative Gram-positive & bacteria \\
& Enveloped viruses & mechion of resistance
\end{tabular}

The level of microbicidal action is divided into three levels of activity and it provides information on the susceptibility of microorganisms. For some microorganisms such as protozoal oocysts and fungi, information is scarce or not available. The effect of microbicide on the microbial cell or in exerting a selective pressure might alter the classification (indicated with the gray boxes) (arrow represents a decrease in microbicide susceptibility).

Adapted from McDonnell and Burke. ${ }^{21}$ 
not sufficient to elicit a selective pressure to silence their expression).

In this context, the emergence of mutator strains has been associated to antibiotic resistance in general and in particular to upregulation of efflux pumps, including the accumulation of compensating mutations, which can reduce potential fitness costs of resistance phenotypes. ${ }^{1,24}$ Although pertinent to the use of antibiotics, mutator strains have not been specifically investigated in response to microbicide exposure. Deficiencies in DNA mismatch repair systems or the ability for a bacterium to acquire exogenous genetic material encoding for resistance mechanisms (e.g., via conjugative plasmids or transposons) need to be better understood. Such mechanisms may contribute to differences in the development of reduced susceptibility or resistance of different bacterial genera/ species/strains exposed to the same microbicide.

The efficacy of microbicides is affected by the degree of metabolic activity of the target bacteria; a low metabolic activity being associated with an ability to survive microbicidal exposure. This may, in turn, contribute to the viable, but nonculturable (VBNC) state, which might be widespread following microbicidal exposure. Although the VBNC state might be more related to survival and/or induction of damage repair mechanisms, it might not be a resistance mechanism per se. However, until more is known, the VBNC state certainly questions the validity of any protocol to measure bacterial viability and resistance, following a microbicidal treatment.

Bacterial biofilms, which are widespread in the environment, add to the number of resistance mechanisms available to bacteria to survive microbicidal exposure. ${ }^{16}$ Bacterial biofilms are less susceptible to microbicides and other antimicrobials than planktonic bacteria for several reasons, including microbicide penetration/quenching, low bacterial cell metabolism, increased mutability and gene transfer, and the presence of bacterial cells in a dormant state. ${ }^{10,16}$

The mechanisms of resistance described above are discussed in the context of microbicide resistance, and only a subset of these is relevant to antibiotic resistance (i.e., cross resistance). Examples of these are shown in Fig. 1 and involve primarily a decrease in uptake (e.g., changes in membrane permeability), or an increase in efflux of the antimicrobial agent. Selective pressure can also result from different resistance determinants occurring in the same mobile genetic element (i.e., coresistance), and this may also confer resistance to antibiotics resulting from microbicide exposure.

\section{Factors related to the usage of microbicides}

Overall, there is little information as to how the conditions of use of biocidal products may affect bacterial reduced susceptibility or resistance. This is partly because parameters in situ might be difficult to measure, or are simply not recorded. Such information is critical for the end-users, manufacturers, and regulators. Factors that drive a decrease in the concentration of a microbicide to levels close to the MIC will be conducive to changes in a bacterial genotype and phenotype.

Parameters, such as actual exposure time, actual residual concentration over time, frequency of application, dilution on application, amount and type of soiling (exogenous organic material) present, which impact on concentration and bioavailability, will have an effect on microbicidal efficacy at application; that is, the level of bacterial survival to be expected (Table 1). The nature of the surface (i.e., porous, nonporous) treated will also have an effect on the efficacy of a microbicide. The effect of soiling in decreasing the activity of certain microbicides has been well documented. ${ }^{28}$

For certain biocidal products, where the microbicide is embedded in the product, bioavailability of the microbicide is paramount and, as such, the concentration release from the products should be known.

Biocidal products are, in general, complex formulations, which, quite apart from containing one or more microbicides, can also have a number of excipients/adjuncts. Such excipients can potentiate the activity of the microbicide or have some antimicrobial activity per se and can comprise surfactant, fragrance wetting or chelating agents. There is little available information on the effect of these different excipients in combination with the microbicide(s) on the efficacy of the biocidal products, although some combinations

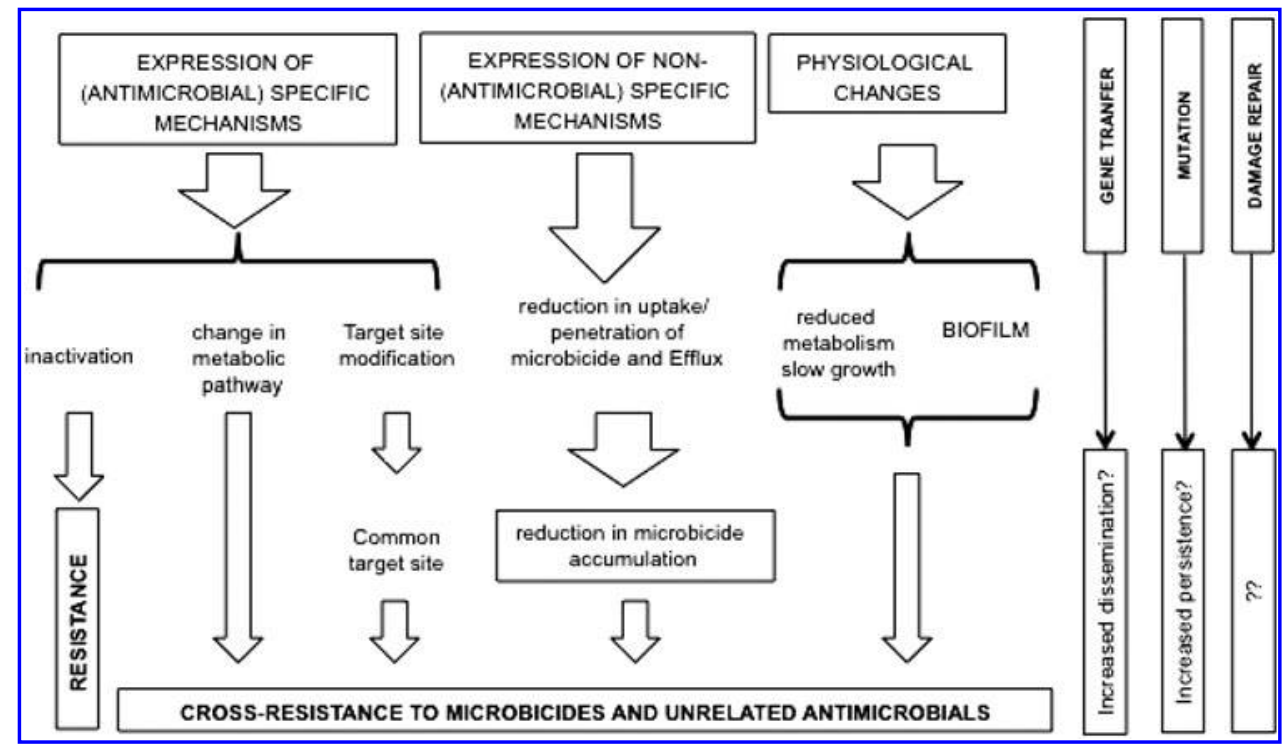

FIG. 1. Mechanisms leading to bacterial resistance and cross resistance to microbicides and unrelated antimicrobials. 
such as chlorhexidine with alcohol or QACs with ethylene diamine tetra acetic acid (EDTA), a chelating agent, have been shown to be synergistic. Generally, the formulation of the biocidal product is not considered when testing for evidence of reduced susceptibility or resistance in bacteria. This should be addressed, since this reflects the actual use of products and formulations should be tested alongside a microbicide. ${ }^{16,31,32}$

\section{The Need for Harmonization of Methodologies to Study Bacterial Reduced Susceptibility and Resistance to Microbicides}

\section{Current methodologies}

Methodologies used to measure a change in susceptibility to a microbicide and whether in situ studies provide better information than in vitro studies have been the subject of considerable debate. The protocol most often used in peerreviewed publications is the determination of the MIC. Although such a protocol, particularly the use of a microdilution method, enables rapid susceptibility screening of target bacteria, a change in MIC is not necessarily an indicator of bacterial resistance to a microbicide, but merely an indication of the propensity of a microbicide to alter the bacterial phenotype. $^{16,27}$ The use of the MBC, or for biofilms, the minimum biofilm eradication concentration, may be more appropriate, as this reflects the lethal nature of a microbicide. ${ }^{3,25} \mathrm{MBC}$ protocols are more complex than MIC protocols, as they require the neutralization of the microbicide, but such protocols can also be reformatted to accommodate high throughput. The use of inactivation kinetics to understand the rate-of-kill with time provides additional information on the interaction between a microbicide and the target bacteria. The shape of the inactivation curve, in particular, can provide potential information as to the presence of bacterial subpopulations that may be less susceptible to a microbicide. ${ }^{16}$ The generation of data describing a kill-curve is laborious and can only be reasonably applied to investigate a limited number of bacteria/microbicide concentration combinations. The use of newer protocols such as flow cytometric analysis may provide a higher throughput methodology to investigate the behavior of single strains (and the presence of subpopulations) exposed to a microbicide ${ }^{35}$ and provide further insight into the nature of the bacterial response.

A major advantage of in vitro experiments is that the test parameters can be controlled accurately to produce reproducible data sets. Unfortunately, parameters such as temperature, contact time, concentration, and the preparation of test inocula-growth media and diluents used, bacterial metabolism at the time of testing, vary widely between studies and this results in poor levels of comparability between them.

There have been only a limited number of in situ studies investigating the effect of microbicide (biocidal products) usage on emerging bacterial resistance. These studies have produced conflicting information on the effect of a microbicide on bacterial community susceptibility to microbicides or antibiotics following application of antibacterial products, at the point of use. ${ }^{4,6,17}$ Although these studies are very valuable and provide realistic information, researchers have to often set their own susceptibility/resistance criteria to facilitate the interpretation and significance of results, mak- ing comparisons between studies more difficult. In addition, because of their nature, in situ studies tend to be less reproducible and more costly than in vitro investigations.

\section{Toward a consensus in methodologies}

Both in vitro and in situ studies are valuable in their own right, but have also suffered from many drawbacks. If in situ investigations may be considered as an ultimate validation, in vitro protocols provide a proof-of-concept reproducibility and confidence in results. In vitro protocols must be improved for their results to be more meaningful (Table 3). The use of environmental isolates, together with parameters reflecting conditions of exposure in vivo are paramount. ${ }^{16}$ Ciusa et al. ${ }^{5}$ established a baseline susceptibility profile of 1388 S. aureus isolates to triclosan and showed that environmental isolates presented different mutations to culture collection isolates. This type of information (i.e., distribution of susceptibility to a microbicide of a population of the target microorganism) should ideally be considered as part of in vitro protocols. Such data are necessary to establish cutoff values for a given bacterium-microbicide combination, which could serve as reference points (e.g., for risk assessment of microbicide resistance), ${ }^{5}$ in analogy to the definition of epidemiological cutoff (ECOFF) values of antimicrobial susceptibility. ${ }^{13}$ In contrast to the ECOFF concept, which is based on wild-type MIC distributions, the microbicide cutoff values should consider both MIC and MBC distributions, and take account of the differences between such distributions from environmental isolates and those from culture collection strains.

There are a number of studies focusing on the use of environmental isolates alongside standard strains obtained from culture collections. We propose that these types of investigation, combining environmental isolates and in situ test conditions should be termed ex situ (i.e., realism-based studies), represent the experimental conditions better.

The study of complex microcosms (i.e., communities of microorganisms) is more challenging, but can provide valuable information, notably on the effect of a microbicide in changing the composition of a complex microcosm. A small number of studies ${ }^{18,19,23}$ in which, complex microcosms were investigated ex situ provide excellent examples of the usefulness of such investigations, highlighting the alterations in the microcosm composition as well as susceptibilities to microbicides.

\section{Potential for predictive methodologies}

Studies that investigate changes in reduced susceptibility or increased resistance to a given microbicide should ultimately aim to determine if there is a risk of microbial resistance development associated with the usage of a specific microbicide. Studies reported in the literature are not designed to predict the risk of microbial resistance development and merely report a susceptibility profile with, or without, associated putative mechanism(s) of resistance. Predictive studies have been hampered by the nature of microbicide interaction with the microbial cells (i.e., multiple target sites) and the different responses that can be expected when investigating, for example, different bacterial species. The complexity of providing a risk-based approach does not 
Table 3. Relevance of IN Vitro Studies to Applications IN SitU

\begin{tabular}{|c|c|c|c|}
\hline In vitro investigation & Aims & $\begin{array}{c}\text { Relevance to applications } \\
\text { in practice }\end{array}$ & Comments \\
\hline Stepwise training & $\begin{array}{l}\text { Reduced susceptibility by } \\
\text { passaging in increasing } \\
\text { concentration of } \\
\text { microbicide }\end{array}$ & $\begin{array}{l}\text { Does not reflect bacterial expo- } \\
\text { sure to a microbicide }\end{array}$ & $\begin{array}{l}\text { Not useful to predict a risk } \\
\text { associated with microbicide } \\
\text { usage }\end{array}$ \\
\hline $\begin{array}{l}\text { Exposure to a high } \\
\text { concentration }\end{array}$ & $\begin{array}{l}\text { Exposure of a high inoculum } \\
\text { to in use concentrations } \\
\text { Does not yield many resistant } \\
\text { bacteria }\end{array}$ & $\begin{array}{l}\text { Presence of high inoculum con- } \\
\text { centration unlikely except for } \\
\text { biofilm }\end{array}$ & $\begin{array}{l}\text { Unrealistic to predict a risk } \\
\text { associated with microbicide } \\
\text { usage }\end{array}$ \\
\hline $\begin{array}{l}\text { Exposure to active } \\
\text { ingredient alone }\end{array}$ & $\begin{array}{l}\text { Understand the effect of } \\
\text { the active on emerging } \\
\text { resistance }\end{array}$ & $\begin{array}{l}\text { Formulations are used in } \\
\text { practice } \\
\text { Formulations can increase or } \\
\text { decrease the activity of the } \\
\text { main ingredient } \\
\text { Formulation excipients may } \\
\text { have intrinsic activity }\end{array}$ & $\begin{array}{l}\text { Only provide information on the } \\
\text { microbicide and might not be } \\
\text { relevant with the biocidal } \\
\text { product }\end{array}$ \\
\hline Use of MIC & $\begin{array}{l}\text { Provide an indication of } \\
\text { possible changes in suscep- } \\
\text { tibility and subsequent } \\
\text { resistance } \\
\text { Exposure to an inhibitory } \\
\text { concentration }\end{array}$ & $\begin{array}{l}\text { High lethal concentrations are } \\
\text { used in practice (in most } \\
\text { applications) }\end{array}$ & $\begin{array}{l}\text { Allow for high-throughput } \\
\text { screening, but not as relevant } \\
\text { as measuring MBC }\end{array}$ \\
\hline $\begin{array}{l}\text { Exposure to low } \\
\text { subinhibitory } \\
\text { concentrations }\end{array}$ & $\begin{array}{l}\text { Induction of resistance } \\
\text { Study of cross resistance and } \\
\text { coresistance }\end{array}$ & $\begin{array}{l}\text { Reflect usage of a low concen- } \\
\text { tration of a biocide (including } \\
\text { leaching and residual activi- } \\
\text { ty) and reduced bioavailabil- } \\
\text { ity (certain biocidal products } \\
\text { and applications) }\end{array}$ & $\begin{array}{l}\text { Relevant for many current ap- } \\
\text { plications and provide infor- } \\
\text { mation on a threshold } \\
\text { concentration associated with } \\
\text { emerging reduced suscepti- } \\
\text { bility and resistance }\end{array}$ \\
\hline $\begin{array}{l}\text { Use of a laboratory } \\
\text { test strain }\end{array}$ & $\begin{array}{l}\text { Allow the work to be } \\
\text { reproduced in different } \\
\text { laboratories }\end{array}$ & $\begin{array}{l}\text { Environmental isolates might not } \\
\text { show the same susceptibility } \\
\text { profile and resistance mecha- } \\
\text { nisms }\end{array}$ & $\begin{array}{l}\text { The use of environmental iso- } \\
\text { lates is more relevant, but } \\
\text { they need to be available to } \\
\text { test laboratories }\end{array}$ \\
\hline
\end{tabular}

Adapted from Maillard and Denyer. ${ }^{16}$

$\mathrm{MBC}$, minimum bactericidal concentration.

mean that the development of such a protocol is unrealistic. Measuring the change in susceptibility profile following a realistic exposure to a given microbicide or biocidal product can yield important information, and provide a risk estimate, or at least a prediction of the risk, associated with the use of a microbicide; this implies that the test inoculum, its nature and metabolic status, is strictly controlled and that the susceptibility profile (MIC/MBC) of the test bacterium to a microbicide and other antimicrobials is established and shown to be reproducible (Fig. 2). When a reproducible change in susceptibility is recorded, further tests to understand the nature of the change, whether it is transient or permanent, the mechanisms associated with the change, and a comparison with the susceptibility profile of environmental isolates can be performed. Two essential criteria for establishing such a protocol are that the test needs to allow for high throughput and that it needs to use realistic in situ parameters that reflect actual conditions during use of the product.

\section{Toward the Development of a Risk Assessment Framework for Microbicide Resistance}

The establishment of a risk assessment framework for microbicide resistance is key for the industry and regulators. Such a framework would provide confidence that the use of biocidal products is safe so far as emerging microbial reduced susceptibility or resistance is concerned. To date, most risk assessments applied in the area of antimicrobial resistance have considered the risk posed by the use of antibiotics in veterinary medicine. ${ }^{22}$ However, for microbicides, there is much less known about the factors associated with the probability of resistance and cross-resistance development, and how these should be considered in risk assessment. In the area of antibiotic resistance in veterinary medicine, current attempts to conduct risk assessments are hampered by the lack of a consensus definition of antibiotic resistance and a lack of scientific data; the development of a risk assessment framework for microbicide resistance development faces similar issues.

The development of semi- or fully quantitative risk assessments on bacterial resistance to microbicides is therefore some distance away and relies on the production of appropriate data (Fig. 3), preferably standardized and working to a widely accepted definition. Focusing on the probability of resistance development only, as opposed to assessing the absolute human health risk, is a more realistic ambition in the near future. This can be considered akin to the entry assessment stage of the OIE risk assessment framework. ${ }^{26}$ An example of a theoretical framework for resistance development is given in Fig. 3. The probability of generating resistant or reduced-susceptibility strains, given a microbicide 


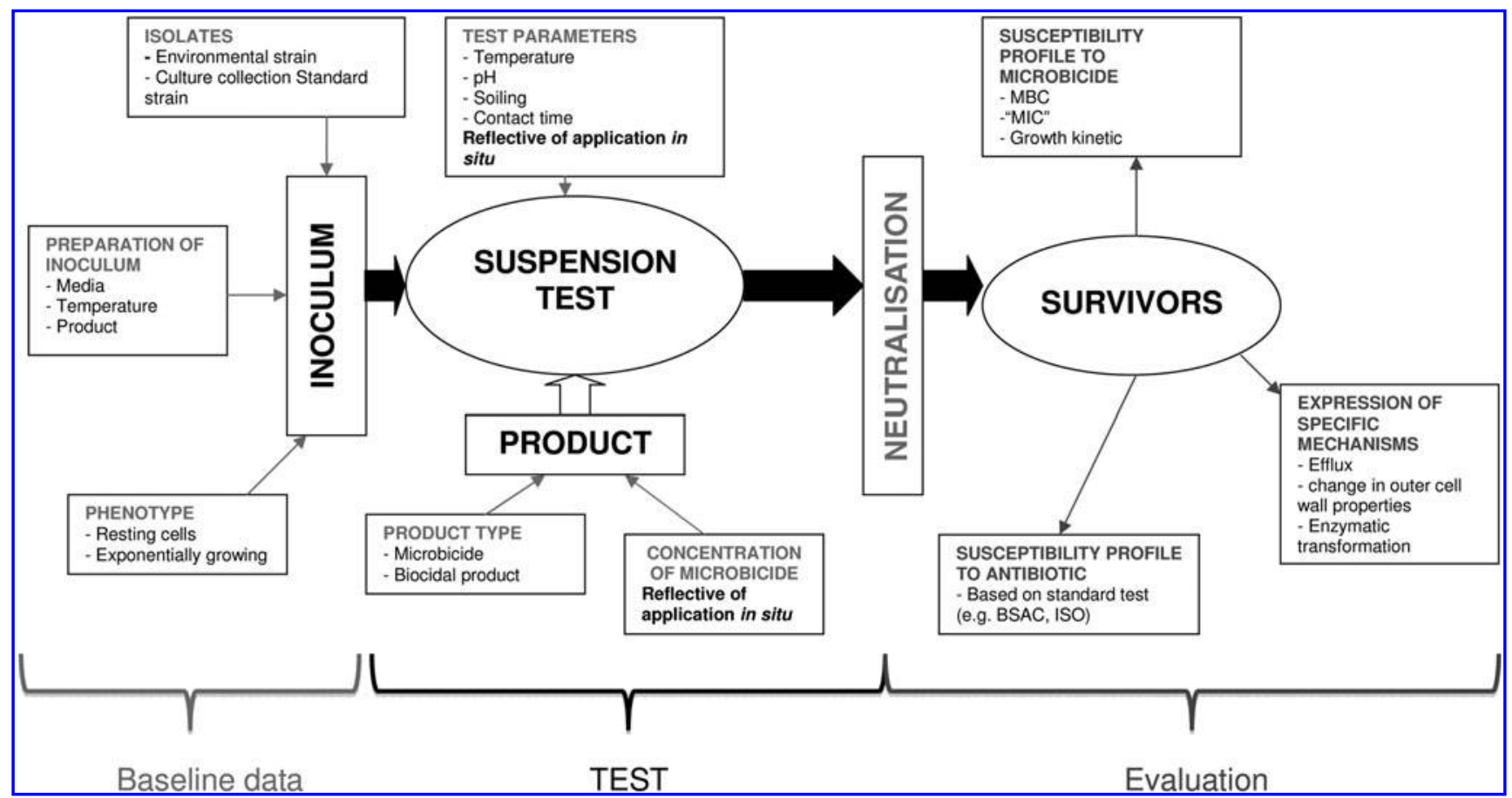

FIG. 2. Example of a flow through method to measure change in bacterial susceptibility profile to microbicides and other antimicrobials.

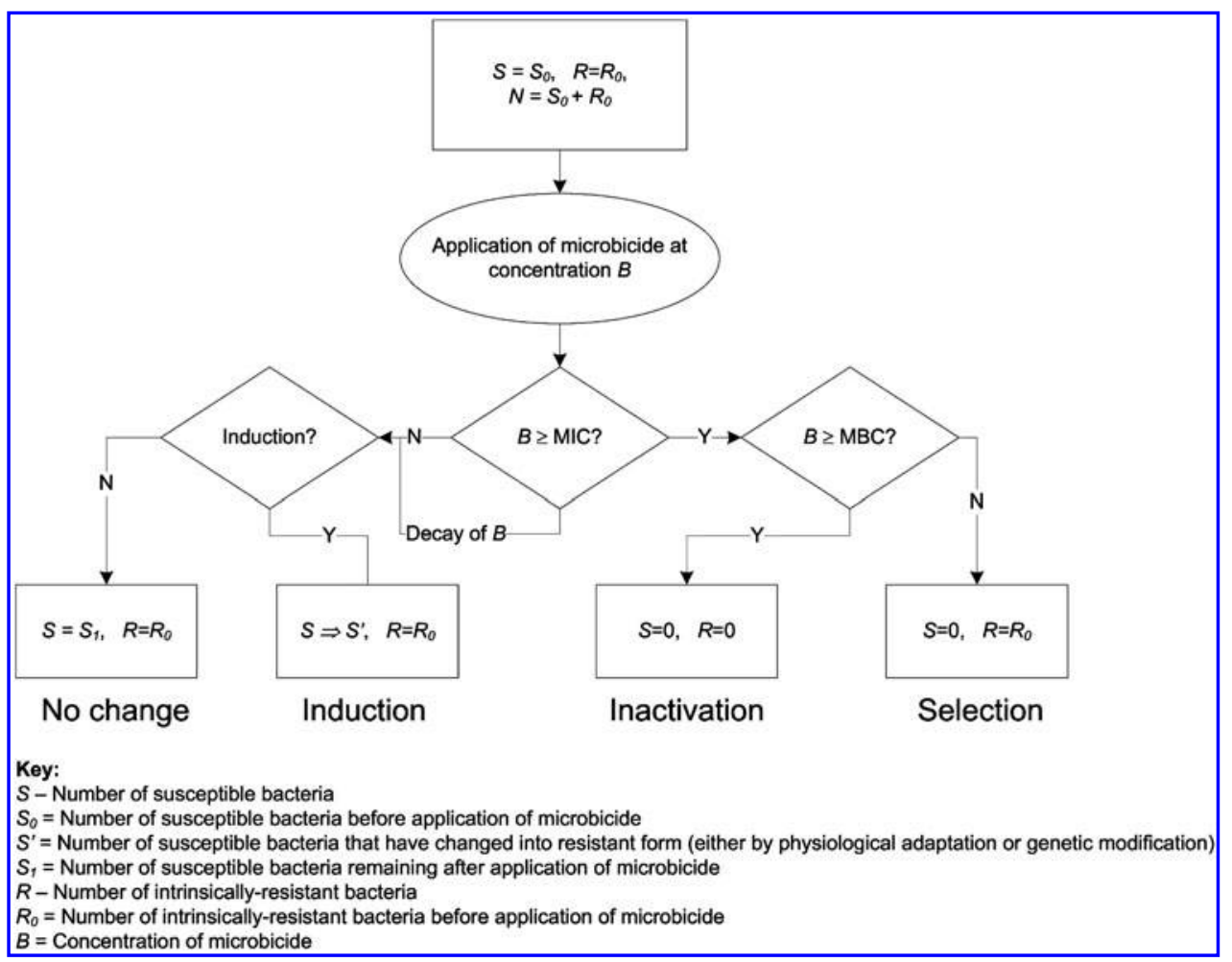

FIG. 3. Theoretical risk assessment pathway approach for microbicide resistance. This figure illustrates a potential theoretical pathway to assist in estimating the probability of emerging microbicide resistance for a specific bacteria/microbicide combination, by following the number of susceptible $(S)$ and microbicide resistant $(R)$ from initial application $\left(S=S_{0}\right.$ and $R=R_{0}$ ) over the course of microbicide application and decay. How resistance does or does not emerge is determined by whether the concentration of the microbicide at any point in time is above or below the MIC and/or minimum bactericidal concentration (MBC). The difference between transient resistance $\left(S^{\prime}\right)$ and established resistance $(R)$ is recognized. 
concentration of $\mathrm{B}, P(R \mid B)$, depends on the concentration of the microbicide, and whether that concentration is (1) sufficient to facilitate mutations that may confer resistance characteristics or (2) sufficient to inactivate all susceptible organisms and, hence, confer a selective advantage to intrinsically resistant organisms. The concentration $B$ is dependent on the initial concentration of application, $B_{0}$, and the decay rate of the microbicide activity over time. The probability of producing a resistant or reduced-susceptibility population of bacteria, $P(R \mid B)$, can be defined as the combined probability of selecting intrinsically resistant strains, $P($ res $\mid B)$, and the probability of inducing transient resistance, $P($ ind $\mid B)$, that is, $P(R \mid B)=P($ res $\mid B)+P($ ind $\mid B)$. Different scenarios may arise depending on the concentration of the microbicide as illustrated in Fig. 3.

The probabilities of selection and induction (i.e., of the expression of resistance mechanism(s)) are dependent on the concentration of the microbicide, and will change as the concentration of the microbicide changes over time. Probabilities for resistance selection will be dependent on the active concentration of the microbicide, the relevant MIC and $\mathrm{MBC}$, and the ratio of resistance to susceptible organisms in the target population of number $N$. The probability of inducing transient resistance will be dependent on the numbers of susceptible bacteria, $S$, and the adaptation or mutation rate in the presence of microbicide at concentration $B$.

To consider the probability of developing cross resistance to antibiotics, the theoretical risk assessment pathway shown in Fig. 3 could be used, but the mechanisms responsible for induction or selection should be known and relevant to antibiotic resistance (e.g., efflux or changes in membrane permeability), as discussed above. This schematic could also be adapted to consider coresistance by introducing an additional step (i.e., following induction or selection) that involves exposure to an antibiotic, but in this case, this is dependent on the resistance determinants (for both microbicide and antibiotic) being colocated on the same mobile genetic element.

Of course, there are many other factors that are important to consider in any safety assessment for biocidal product approval, of which, the potential for development of microbicide resistance is only one. However, there is considerable value in trying to identify the risk factors involved in selection and/or induction of microbicide resistance under conditions of use of biocidal products. The suggested framework is a proposal from a group of experts to describe the salient pathways for microbicide resistance and highlight some of the crucial data requirements (e.g., MIC/ MBCs of biocide and concentrations of biocide in relevant environments over time). As such, it provides a proposal for the inclusion of such factors and approaches into established processes of any human health risk assessments for safety assurance.

Another possible option for risk assessment in the short term would be to outline a qualitative approach for risk prioritization such as risk ranking of microbicides in terms of their likelihood to induce or select for bacteria with decreased susceptibility (possibly based on criteria layout in Table 1). Risk ranking along these lines might be appropriate and achievable for a limited number of microbicides on the basis of our current knowledge, and would be useful to inform risk management.

\section{A Way Forward for Microbicidal Research}

This position document has reflected on current research and available data and makes a number of key research recommendations.

\section{Harmonization of terms and methods}

Global harmonization is a key requirement, particularly on the protocols used to measure changes in susceptibility and mode(s) of action. Microbicide research is at present disparate and data generated are difficult to compare. We recommend the use of parameters that reflect better the conditions found in practice, and with this in mind, the use of ex situ protocols are more appropriate.

We recommend that initiatives are progressed to encourage global harmonization of protocols used to measure changes in susceptibility and mode(s) of action. Such protocols should consider parameters that reflect better conditions found in practice, including the use of more appropriate ex situ protocols. This will enable research and other studies to be better compared.

\section{Generating baseline susceptibility information}

The use of culture collection standard strains might not reflect the behavior of environmental bacteria. The use of environmental isolates is thus recommended (ex situ protocol). Ideally, the susceptibility of a large number of environmental isolates (same genus, species) to microbicides should be determined to provide background information on a specific bacterial genera/species. This information should be made globally available.

\section{Understanding bacterial resistance and dissemination}

There is a paucity of information on the interaction(s) of microbicides (notably at a low concentration) with the bacterial cells. The most studied microbicide is triclosan, but this is an exception. Other microbicides, notably those used in preservative systems (e.g., isothiazolinones, pyrithiones) have shown an ability to allow the development of reduced susceptibility/resistance in selected bacteria and yet these mechanisms are poorly understood. There has been an increase in omic studies to understand better the genetic mechanisms of resistance. Such investigations should be encouraged, alongside more traditional methods. The dissemination and maintenance of mobile genetic elements should be better investigated, as this presents an important risk factor for emerging bacterial resistance to unrelated compounds, including therapeutic antibiotics.

\section{Biofilms}

The study of biofilms, including complex biofilms, is a challenge, although they may better represent certain environmental and clinical settings. Laboratory studies based on environmental biofilms grown in fermentors using realistic environmental parameters ( $e x$ situ) should be encouraged.

\section{Education and data mining}

Microbicides are an important resource that needs to be well managed to preserve their efficacy. A better understanding of their conditions of use and consumer habit is necessary to establish reflective ex situ studies and, 
ultimately, predict the risk associated with a particular microbicide and its application. This also means that both end users and industry need to gain a better understanding on the appropriate use of microbicide and the risks associated with the misuse of biocidal products.

\section{Conclusions}

Among the different hygiene measures, those dealing with antisepsis and disinfection are recognized as a cost-effective means to reduce the infectious disease burden. Microbicides have a vital role in preventing infectious disease transmission in the home, but they should not be used indiscriminately and a risk-based (targeted) approach to hygiene should be recommended. ${ }^{2}$ One has to bear in mind that the inappropriate and overuse of microbicides might also have a detrimental effect on human health and the environment. The inclusion of microbicides in products and product claims (e.g., bactericidal action) should be carefully reassessed and should not solely serve a commercial purpose, but as a need for microbialcontrol/prevention. Thus, education about how microbicides are useful in a domestic environment is very important.

This position document calls for harmonization of definition and methodology to unite microbicidal research. A number of definitions have been proposed reflecting on the use of specific protocols to assess changes in bacterial susceptibility when exposed to a microbicide. A realistic risk assessment framework is essential for assessing the implications of microbicide use, for both the industry and the consumer (end user) and regulators.

Hopefully, this position document will encourage scientists in the field of microbicide research to move toward developing a unified risk-based approach to microbicide production and the subsequent use of such products in the industry, hospitals, and home.

\section{Acknowledgments}

Although colleagues at Unilever participated in the discussion, the writing of this white paper remained an academic exercise, and was also able to consider important applied regulatory and industrial interests. In this respect, we would like to thank SEAC for organizing the workshop on bacterial resistance in June 2012, and in particular A. Amezquita, P. McClure, and N. Ronnie.

\section{Transparency Declaration}

This position document is the result of a 2-day workshop organized by SEAC (Safety \& Environmental Assurance Centre, Unilever) to which all the authors were invited to attend. SEAC provided the meeting facility and covered the travel expenses of all participants.

Although colleagues at Unilever participated in the discussion, the writing of this white paper remained an academic exercise, but with applied regulatory and industrial interests.

\section{Disclosure Statement}

None of the authors are employees of Unilever.

\section{References}

1. Andersson, D.I. 2003. Persistence of antibiotic resistant bacteria. Curr. Opin. Microbiol. 6:452-456.
2. Bloomfield, S.F., M. Exner, C. Signorelli, K.J. Nath, and E.A. Scott. 2012. The chain of infection transmission in the home and everyday life settings, and the role of hygiene in reducing the risk of infection. Available at www.ifh-homehygiene.com/best-practice-review/chain-infection-transmissionhome-and-everyday-life-settings-and-role-hygiene, accessed 8 May 2013. (Online.)

3. Ceri, H., M.E. Olson, C. Stremick, R.R. Read, D. Morck, and A. Buret. 1999. The Calgary biofilm device: new technology for rapid determination of antibiotic susceptibilities of bacterial biofilms. J. Clin. Microbiol. 37:1771-1776.

4. Cole, E.C., R.M. Addison, J.R. Rubino, K.E. Leese, P.D. Dulaney, M.S. Newell, J. Wilkins, D.J. Gaber, T. Wineinger, and D.A. Criger. 2003. Investigation of antibiotic and antibacterial agent cross-resistance in target bacteria from homes of antibacterial product users and nonusers. J. Appl. Microbiol. 95:664-676.

5. Cole, E.C., R.M. Addison, P.D. Dulaney, K.E. Leese, H.M. Madanat, and A.M. Guffey. 2011. Investigation of antibiotic and antibacterial susceptbility and resistance in Staphylococcus form the skin of users and non-users of antibacterial wash products in home environments. Int. J. Microbiol. Res. 3:90-96.

6. Ciusa, M.L., L. Furi, D. Knight, et al. 2012. A novel resistance mechanism to triclosan that suggests horizontal gene transfer and demonstrates a potential selective pressure for reduced biocide susceptibility in clinical strains of Staphylococcus aureus. Int. J. Antimicrob. Agents 40:210-220.

7. Dancer, S.J. 2009. The role of environmental cleaning in the control of hospital-acquired infection. J. Hosp. Infect. 73:378385.

8. Denyer, S.P., and G.S.A.B. Stewart. 1998. Mechanisms of action of disinfectants. Int Biodeter. Biodegrad. 41:261-268.

9. Directive 98/8/EC of the European Parliament and of the Council. Available at http://ec.europa.eu/environment/ biocides/, accessed 24 February 2013. (Online.)

10. Gilbert, P., T. Maira-Litran, A.J. McBain, A.H. Rickard, and F.W. Whyte. 2002. The physiology and collective recalcitrance of microbial biofilm communities. Adv. Microb. Physiol. 46:202-256.

11. Gomez Escalada, M., A.D. Russell, J.-Y. Maillard, and D. Ochs. 2005. Triclosan-bacteria interactions: single or multiple target sites? Lett. Appl. Microbiol. 41:476-481.

12. Heath, R.J., and C.O. Rock. 2000. A triclosan-resistant bacterial enzyme. Nature 406:145-146.

13. Kahlmeter, G., D.F.J. Brown, F.W. Goldstein, A.P. MacGowan, J.W. Mouton, A. Osterlund, A. Rodloff, M. Steinbakk, P. Urbaskova, and A. Vatopoulos. 2003. European harmonization of MIC breakpoints for antimicrobial susceptibility testing of bacteria. J. Antimicrob. Chemother. 52:145-148.

14. Linley, E., S.P. Denyer, G. McDonnell, S. Simons, and J.-Y. Maillard. 2012. The use of hydrogen peroxide as a biocide: new consideration of its mechanisms of microbicidal action. J. Antimicrob. Chemother. 67:1589-1596.

15. Maillard, J.-Y. 2005. Usage of antimicrobial biocides and products in the healthcare environment: efficacy, policies, management and perceived problems. Ther. Clin. Risk Manag. 1:340-370.

16. Maillard, J.-Y., and S.P. Denyer. 2009. Emerging bacterial resistance following biocide exposure: should we be concerned? Chem. Oggi. 27:26-28.

17. Marshall, B.M., E. Robleto, T. Dumont, and S.B. Levy. 2012. The frequency of antibiotic-resistant bacteria in homes differing in their use of surface antibacterial agents. Curr. Microbiol. 65:407-415. 
18. McBain, A.J., R.G. Bartolo, C.E. Catrenich, et al. 2003. Exposure of sink drain microcosms to triclosan: population dynamics and antimicrobial susceptibility. Appl. Environ. Microbiol. 69:5433-5442.

19. McBain, A.J., R.G. Ledder, L.E. Moore, C.E. Catrenich, and P. Gilbert. 2004. Effects of quaternary-ammonium based formulations on bacterial community dynamics and antimicrobial susceptibility. Appl. Environ. Microbiol. 70:3449-3456.

20. McDonnell, G., and A.D. Russell. 1999. Antiseptics and disinfectants: activity, action, and resistance. Clin. Microbiol. Rev. 12:147-179.

21. McDonnell, G., and P. Burke. 2011. Disinfection: is it time to reconsider Spaulding? J. Hosp. Infect. 78:163-170.

22. McEwen, S.A. 2012. Quantitative human health risk assessments of antimicrobial use in animals and selection of resistance: a review of publicly available reports. Rev. Sci. Tech. 31:261-276.

23. Moore, L.E., R.G. Ledder, P. Gilbert, and A.J. McBain. 2008. In vitro study of the effect of cationic biocides on bacterial population dynamics and susceptibility. Appl. Environ. Microbiol. 74:4825-4834.

24. Morero, N.R., M.R. Monti, and C.E. Argaraña. 2011. Effect of ciprofloxacin concentration on the frequency and nature of resistant mutants selected from Pseudomonas aeruginosa mutS and mutT hypermutators. Antimicrob. Agents Chemother. 55:3668-3676.

25. Moskowitz, S.M., J.M. Foster, J. Emerson, and J.L. Burns. 2004. Clinically feasible biofilm susceptibility assay for isolates of Pseudomonas aeruginosa from patients with cystic fibrosis. J. Clin. Microbiol. 42:1915-1922.

26. [OIE] Office International des Epizooties. 2012. Handbook on Import Risk Analysis for Animals and Animals products, Volume I. Introduction and Qualitative Risk Analysis. Office International des Epizooties, Paris, France, pp. 30-31.

27. Russell, A.D., and G. McDonnell. 2000. Concentration: a major factor in studying biocidal action. J. Hosp. Infect. 44:1-3.

28. Rutala, W.A., and D.J. Weber. 1999. Infection control: the role of disinfection and sterilization. J. Hosp. Infect. 43:S43S55.

29. Sattar, S.A., J. Tetro, and V.S. Springthorpe. 1999. Impact of changing societal trends on the spread of infectious diseases in American \& Canadian homes. Am. J. Infect. Control 27: S4-S21.

30. SCCS. 2010. Opinion on triclosan antimicrobial resistance. Available at http://ec.europa.eu/health/scientific_committees/consumer_safety/docs/sccs_o_023.pdf, accessed 25 February 2013. (Online.)

31. SCENIHR. 2009. Assessment of the Antibiotic Resistance Effects of Biocides. Available at http://ec.europa.eu/health/ ph_risk/committees/04_scenihr/docs/scenihr_o_021.pdf, accessed 25 February 2013. (Online.)

32. SCENIHR. 2010. Research strategy to address the knowledge gaps on the antimicrobial resistance effects of biocides. Available at http://ec.europa.eu/health/scientific_committees/emerging/docs/scenihr_o_028.pdf, accessed 25 February 2013. (Online.)

33. U.S. Environmental Protection Agency (Oct. 2010). Standard Operating Procedure for OECD Quantitative Method for Evaluating Bactericidal Activity of Microbicides Used on Hard, Non-Porous Surfaces. Office of Pesticide Programs Ft. Meade, MD. Available at www.epa.gov/pesticides/ methods/atmpmethods/MB-25-00.pdf, accessed February 2013. (Online.)

34. Webber, M.A., N.G. Coldham, M.J. Woodward, and L.J.V. Piddock. 2008. Proteomic analysis of triclosan resistance in Salmonella enteric serovar Typhimurium. J. Antimicrob. Chemother. 62:92-97.

35. Whitehead, R.N., T.W. Overtn, C.L. Kemp, and M.A. Webber. 2011. Exposure of Salmonella enterica serovar Typhimurium to high level biocide challenge can select multidrug resistant mutants in a single step. PLoS One 6:e22833.

Address correspondence to: Jean-Yves Maillard, BSc, PhD

Cardiff School of Pharmacy and Pharmaceutical Sciences Cardiff University

King Edward VII Avenue Cardiff CF10 3NB

United Kingdom

E-mail: maillardj@cardiff.ac.uk 